\title{
High SMAS face lift: clinical experience
}

\author{
Zhijun Wang, MD, PhD', Xiaoyan Ma, MM², Lixiang Yang, BSMed², Yan Wang, $\mathrm{MM}^{3}$, Lili Chen, MM, BSMed², \\ Hang Lv ${ }^{2}$ \\ ${ }^{1}$ Institute of Dalian University Plastic Surgery, Beijing, P.R. China, ${ }^{2}$ Ode BeauCare Clinic, Beijing, P.R. China, ${ }^{3}$ Chong Qing BeauCare Clinic, \\ Chong Qing, P.R. China
}

\begin{abstract}
Background: The ultimate goal of facelift is to lift the sagging soft tissue as much as possible, so as to restore them to the original anatomical position for facial rejuvenation.

Objective: In our High-SMAS facelift, the SMAS-platysma flap were tighten strongly, so as to obtain full and youthful facial morphologic characteristics. In addition, the effectiveness of high-SMAS was evaluated in this paper.

Methods: A total of 86 cases of SMAS face lift were performed in 22 months from January 2015 to November 2016. High SMAS technique was applied in 39 cases of them. All the 39 patients were female averaged 44 (29-65) years old. Postoperative follow-up wascarried out in 18 cases for an average of 13 months (4-22 months). After the SMAS-platysma flap was dissected in the lower face and neck, the key point of operating is focus on:The middle temporal fascia and superficial temporal fascia flap was dissected carefully. Break off the ligaments medial to the zygomatic arch and on the malar process exactly, and pay attention to protect the facial nerve. So that the high-SMAS and even higher-SMAS flap can be dissected.

Results: In all the 18 cases followed up, most (11/18) obtained a clear mandibular margin after operation and scored even full mark. Perfect nasolabial fold improvement was achieved in few (7/18). In terms of Ogee curve evaluation, most (15/18) made it to the level of "acceptable", which was shared by the evaluation of lower eyelid shortening effects (13/18). Very satisfied indicators as follow: the obtuse jowl line becomes clear, midface "ogee curve" is vary from linear to curves, and the nasolabial sulcus have been improved.

Conclusion: High-SMAS Facelift is one of the most effective rhytidectomy, the most prominent parts of its effect including the improvement of midface and jowl line contour.

Level of Evidence: IV
\end{abstract}

Keywords: high SMAS; facelift; effectiveness; evaluate

\section{Introduction}

The ultimate goal of facelift is to lift the sagging soft tissue as much as possible, so as to restore them to the original anatomical position for facial rejuvenation. However, when dissecting skin flaps extensively, the issue of blood circulation in them calls for the most consideration. A larger scope of dissection means worse blood circulation that postpones the recovery time and, though rarely, might even lead to flap tip necrosis. Additionally, the extensive dissection of SMAS flaps risks damaging the branches of the facial nerve, which can be serious. In order to optimize the tightening of skin flaps, the authors expanded flap dissection as much as possible. Generally, the dissection is narrowest at the temporal site, but extends as it moves down

Received August 21 2017, Revised October 11 2017, Accepted October 112017

Corresponding author: Zhijun Wang, Institute of Dalian University Plastic Surgery, 21st Century Hotel, No. 40, Brightma Bridge Road, Chaoyang District, Beijing 100016, P.R. China

Tel: 86-13998552625, Fax: 86-13998552625, E-mail: 13998552625@163.com

This is an Open Access article distributed under the terms of the Creative Commons Attribution Non-Commercial License (http://creativecommons.org/licenses/by-nc/4.0), which permits unrestricted non-commercial use, distribution, and reproduction in any medium, provided the original work is properly cited.

Copyright (c) 2017. Korean Society of Korean Cosmetic Surgery (KSKCS) Korean College of Cosmetic Surgery (KCCS). 
until across the median line at the neck. Only in this way it is possible to lift the loose cervical skin hugely to the superior and posterosuperior directions. According to the clinical experience of the authors, the SMAS-platysma flap needs to be dissected across a large scope mainly because most zygomatic ligaments [1], and all SMAS-malar ligaments and suspensory platysma ligaments [2] have to be dissected and cut. For these necessary procedures, the temporal dissection of SMAS needs to be carried across the deep plane of the orbicularis oculi muscle to the external obit rim; the zygomatic dissection has to reveal the zygomaticus major; the buccal dissection should reach the surface of the buccal fat pad at the anterior border of the masseter, while the mandibular and submandibular dissection needs to visualize facial arteries.

\section{Materials and methods}

A total of 86 cases of SMAS face lift were performed in 22 months from January 2015 to November 2016. High-SMAS technique was applied in 39 cases of them. All the 39 patients were female averaged 44 (29-65) years old. Postoperative follow-up was carried out in 18 cases for an average of 13 months (4-22 months). The standard for evaluating surgery outcome was shown in Table 1, covering six items: A-jowl line, B-ogee curve, C-nasolabial fold, D-jowl (sagging of jowl), E-submental fullness, F-lower eyelid vertical distance (Fig. 1).

\section{Surgical technique}

1. Skin dissection involves a smaller area at the temporal region than neck. As the dissection moves down, the span varies as follows (Fig. 2): $5.5 \mathrm{~cm}-6.5 \mathrm{~cm}$ from the crus of helix to the lateral canthus (AB); $6.5 \mathrm{~cm}-7.5 \mathrm{~cm}$ from crus of helix to the zygomatic process (AC); $5.0 \mathrm{~cm}-5.5 \mathrm{~cm}$ in front of the earlobe at the horizontal line from earlobe to the angulus oris (ED); 8.5 $\mathrm{cm}-9.5 \mathrm{~cm}$ from the earlobe to the anterior inferior direction along the mandible line (EF); $5.0 \mathrm{~cm}-6.5 \mathrm{~cm}$ vertical distance below the earlobe.The separation of the neck is continuous with the midline.

2. Submental platysmaplasty is performed firstly (Fig. 3). The superficial and deep layers of the platysma are separated ac-

Table 1. Standard for high SMAS face lift outcome evaluation

\begin{tabular}{lllllll}
\hline \multicolumn{1}{c}{ Standard } & \multicolumn{1}{c}{ A } & \multicolumn{1}{c}{ B } & \multicolumn{1}{c}{ C } & \multicolumn{1}{c}{ D } & \multicolumn{1}{c}{ E } & \multicolumn{1}{c}{ F } \\
\hline Perfect & Very clear & Very good & Nearly removed & Removed & Removed, acute-angled & Shorten obviously \\
& A1=3 scores & B1=2 scores & C1=2scores & D1=1 score & E1=1 score & F1=1 score \\
Good & Clear & Good & Diminished & Diminished & Diminished & Shortened \\
& A2=2 scores & B2=1.5 scores & C2 $=1.5$ scores & D2=0.8 score & E2=0.8 score & F2=0.8 score \\
Acceptable & Moderate & Moderate & Slightly diminished & Slightly diminished & Slightly diminished & Slightly shortened \\
& A3=1 score & B3=1 score & C3=1 score & D3=0.5 score & E3=0.5 score & F3=0.5 score \\
Unimproved & Ineffective & Ineffective & Ineffective & Ineffective & Ineffective & No shortened \\
& 0 score & 0 score & 0 score & 0 score & 0 score & 0 score \\
\hline
\end{tabular}

A, jowl line; B, ogee curve; C, nasolabial fold; D, jowl (sagging of jowl); E, submental fullness; F, lower eyelid vertical distance.

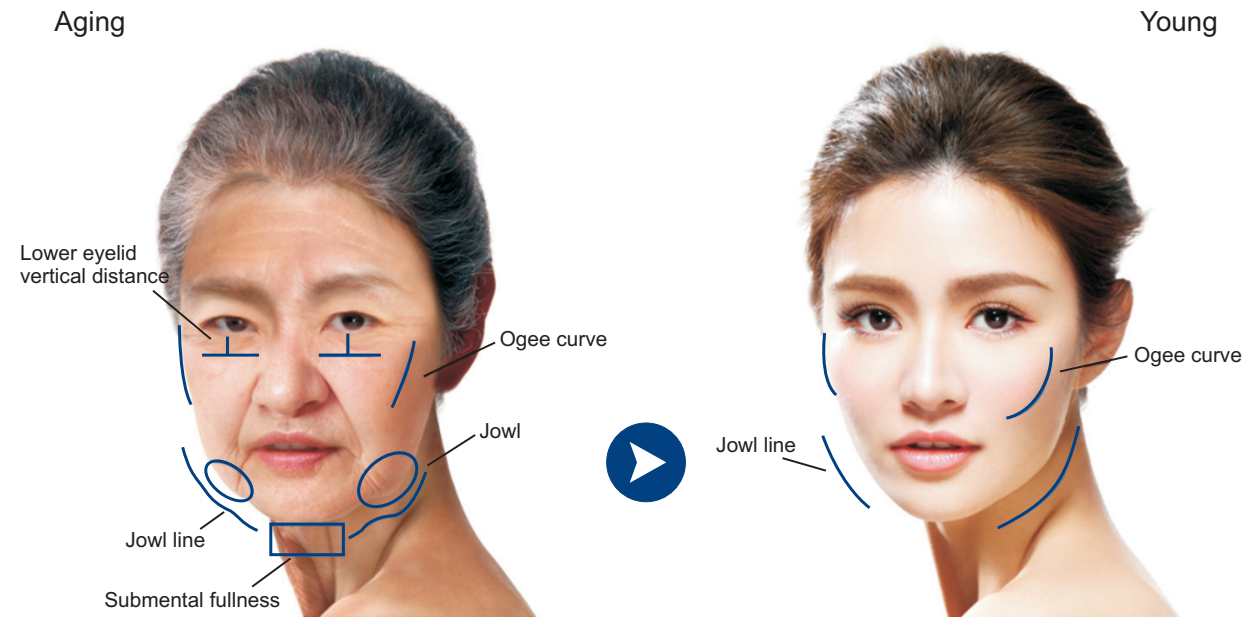

Fig. 1. Aging and young facial features. 

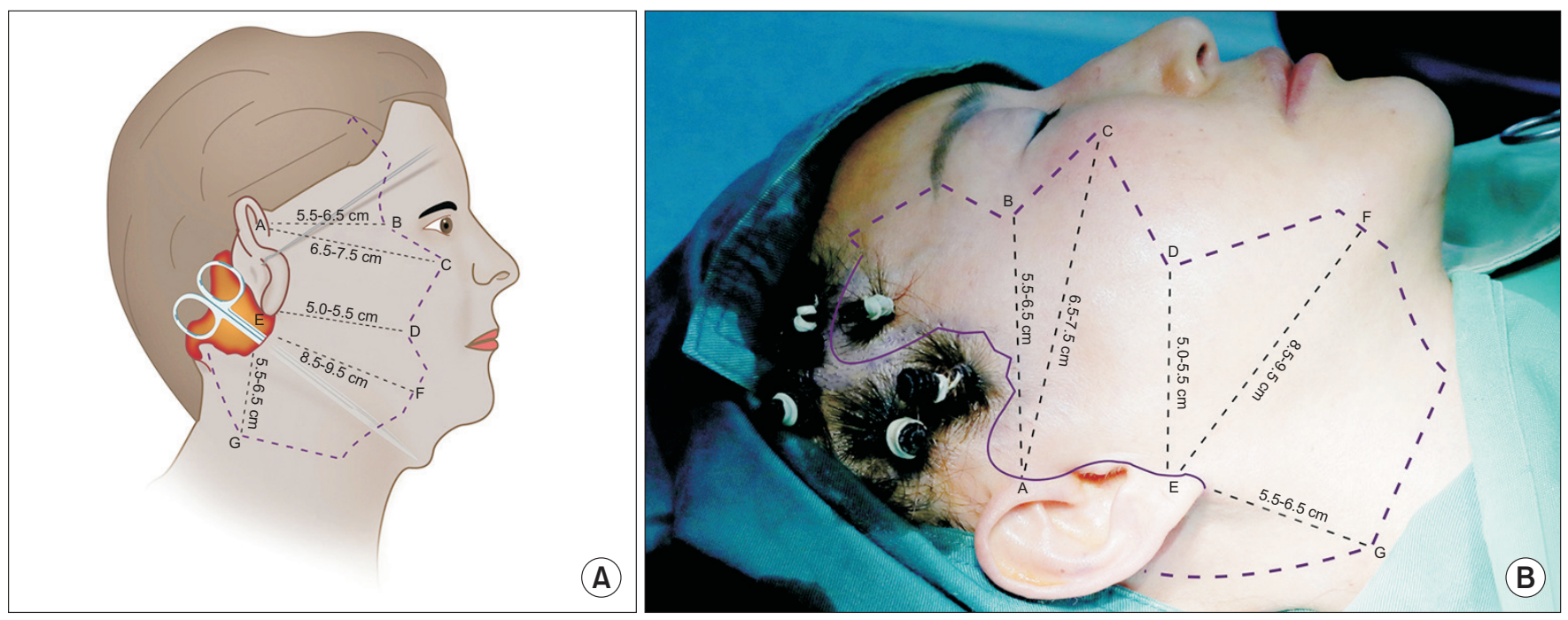

Fig. 2. The extensive subcutaneous dissection range.
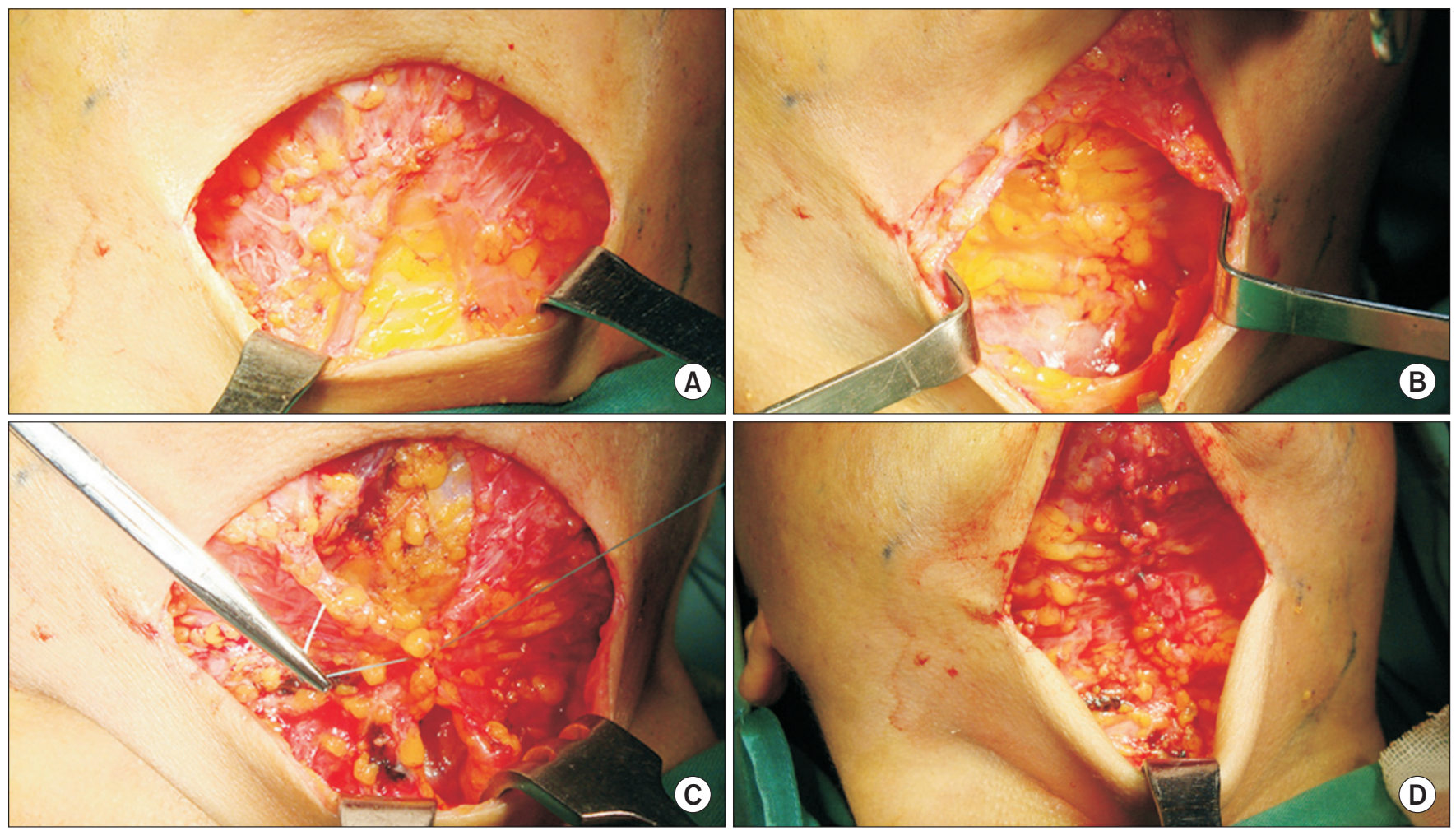

Fig. 3. Submental platysmaplasty is performed.

cording to the Feldman JJ technique [3] (Fig. 3A, B). Following that, the anterior edges of the platysma are sutured using locking suture at the median line (Fig. 3C, D) .

3. The boundaries of high SMAS flap dissection are shown in Fig. 4A. The separation of the upper bound of SMAS is critical, as the flap goes higher, it becomes thinner, which adds more risk to the surgery. For thin patients or whose temporal region not too depressions, the incision line for the superior boundary of SMAS flap dissection should be lower than the horizontal line to the lateral canthus, while for heavier patients with medianto-heavy recessing tempus, the incision line should be higher than that. 

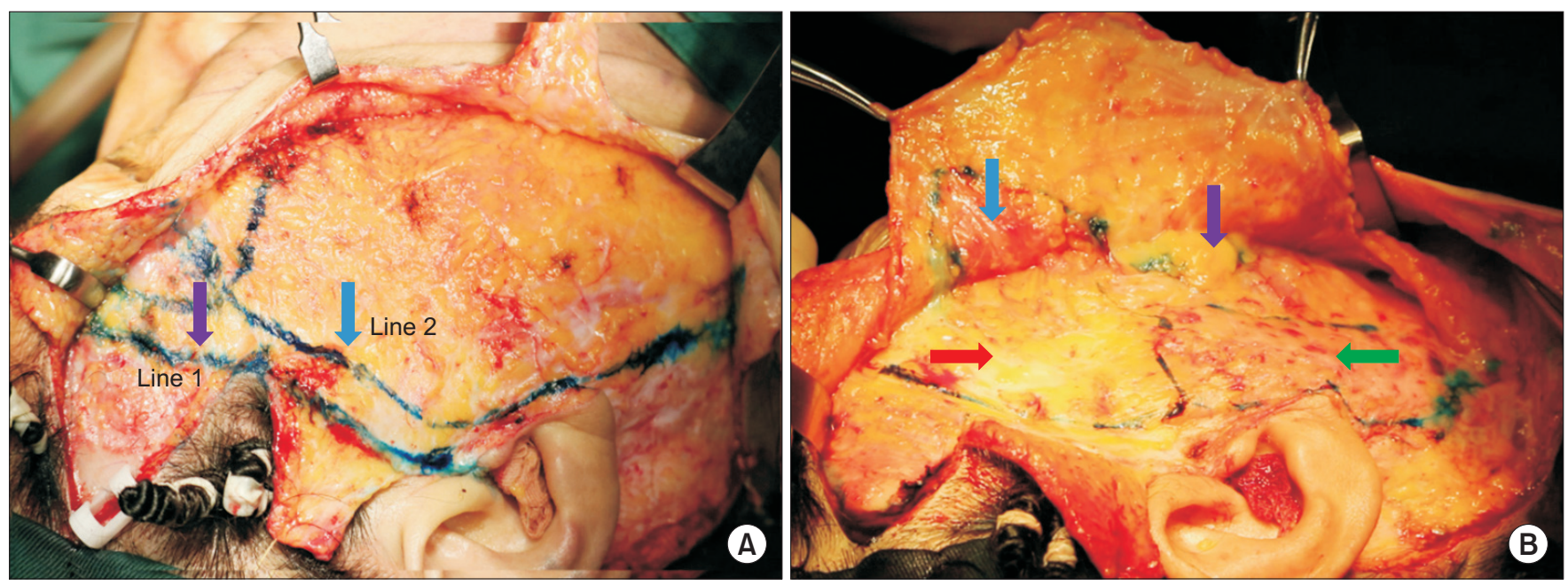

Fig. 4. High-SMAS incision and separation range. (A) Line 1 is the connecting line between the $2 \mathrm{~cm}$ above the eyebrow and the tragus, which is the surface projection of the most superior facial nerve. Line 2 is the incision line of high SMAS. (B) The SMAS-flap was separated integrallty, which is thick and strong. The blue arrow refers to the orbicularis muscle, purple arrow is the buccal fat pad, red arrow is the temporal middle fascia, and green arrow is the parotid gland capsule.

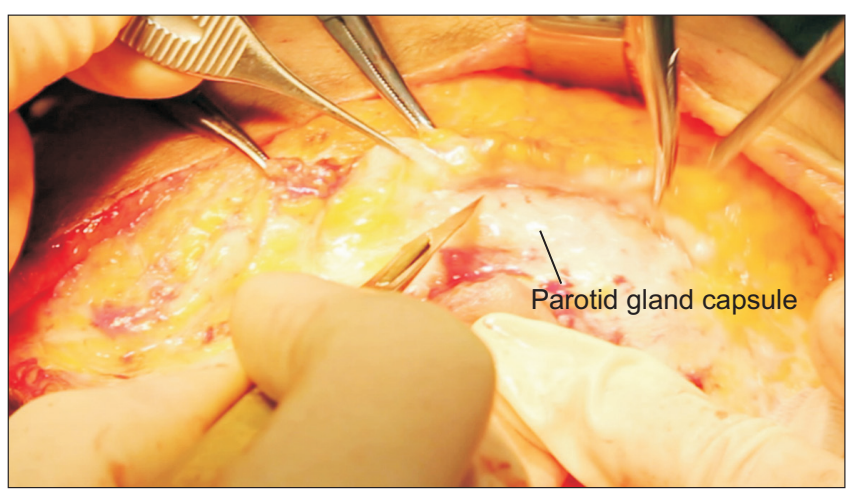

Fig. 5. White and compact parotid gland capsule, which indicates the best depth of SMAS flap dissection.

4. It is the key to separate and form the temporal superficial fascia SMAS flap in high SMAS flap dissection. Because the temporal superficial fascia and the temporal middle fascia [4] are not easily distinguishable in more than half of the patients (Fig. 4B). It is recommended that the dissection begins from the parotideomasseteric region under the zygomatic arch.

\section{Parotid gland capsule: the key indicator for the SMAS} flap dissection

A longitudinal incision is made at the anterior side of the tragus, followed by sharp dissection to the superficial of the white and compact parotid gland capsule, which indicates the best depth of SMAS flap dissection (Fig. 5) . Sometimes, the capsule will be ripped during the dissection. This is not desired even with a ripping capsule but considering that fistula can be pre- vented. It is still better in contrast to a superficial dissection that increases the difficulty of dissection and might even cause the plasty of SMAS flap to fail. After that, the dissection is continued along the surface of the parotid gland capsule, and carried forward into the premasseter space [5] , and up along the same horizontal plane that guarantees a safe separation between the superficial temporal fascia and the middle temporal fascia. The superficial temporal fascia consists of compact connective tissue that is similar in color to the loose luminous yellow fat forming the temporal middle fascia. It seems even more difficult to distinguish the two with bleeding. However, careful inspection can easily detect the difference.

Cutting off ligaments and SMAS-platysma flap plasty: risky and necessary

Zygomatic ligaments are patch-like [1] and run along the transverse facial artery and the zygomatic branch of the facial nerve (Fig. 6). It is necessary to dissect and cut the zygomatic ligaments behind the zygomaticus major to better tighten and advance high SMAS flap to achieve a good effect. Zygomatic ligaments share the same color with normal tissues but they are hard and tough in most people , and usually already seen $4.5 \mathrm{~cm}$ anterior to the tragus on the surface of parotid gland, accompanied by the transverse facial artery. The ligation and electrocoagulation here should be cautious due to the neighboring zygomatic branch of facial nerve. Following the cutting of the main part of zygomatic ligaments, the corresponding SMAS flap becomes movable. As for the pseudo masseteric 

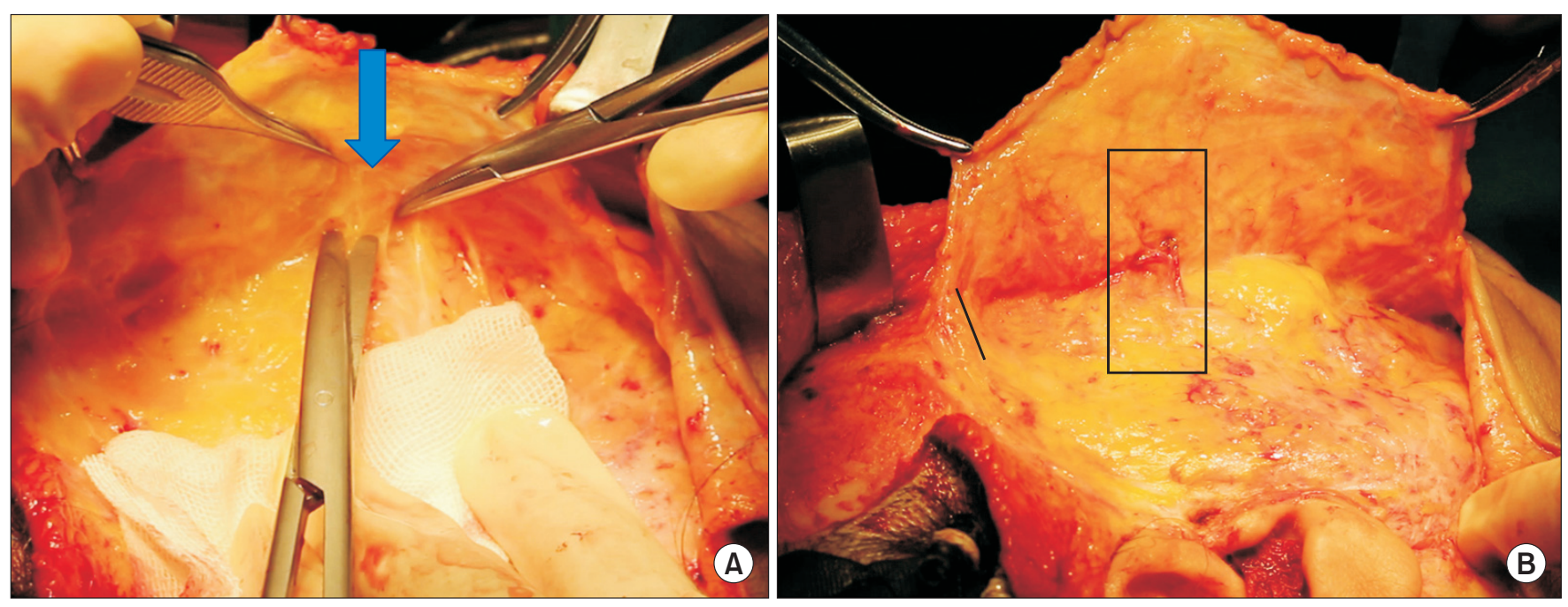

Fig. 6. Zygomatic ligaments. (A) The blue arrow shows the tough and firm zygomatic arch ligament. (B) The black box is the distribution area of the zygomatic arch ligament and transverse artery.

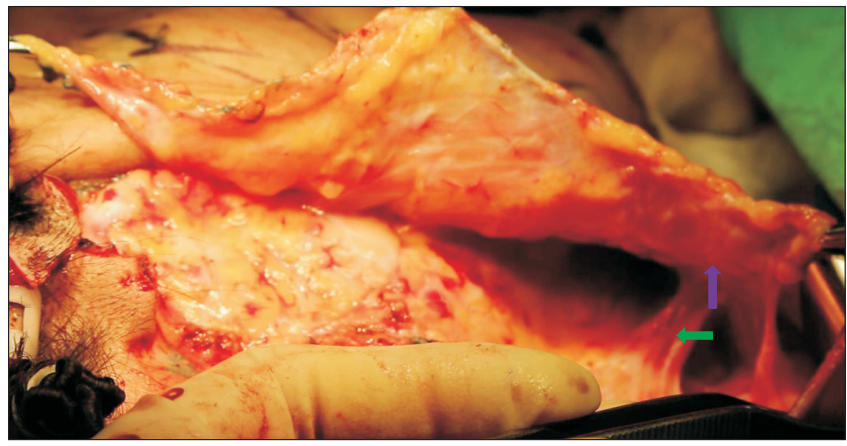

Fig. 7. Suspensory platysma ligament are located between the angle of mandible and the sternocleidomastoid muscle. The purple arrow refers to the platysma, and the green arrow refers to the suspensory platysma ligament.

ligaments [1] (also referred to as SMAS-malar ligaments by the authors [2]), it is fine to leave them untouched unless the buccal fat pad (BFP) needs to be dealt with. In order to better expose and tighten BFP, the authors dissect and cut most masseteric ligaments. Masseteric ligaments should be pulled like a rubber band before being scissored slightly away from the masseter fascia. Lastly, the BFP is pulled out and sutured at the inferior zygomatic recess or on the parotid gland capsule.

Suspensory platysma ligaments (Fig. 7) [2], double-fold and patch-like, are located between the mandible angle and the sternocleidomastoid muscle, with the superficial jugular vein behind them. They should be dissected and cut tightly against the superficial plane, which is significant for tightening the skin and platysma across the mandible.
The perpendicular to the anterior border of masseter: the most difficult part of SMAS flap plasty

The dissection of SMAS flaps, especially high SMAS-platysma flap, is challenging to either move on or retreat when it comes to the perpendicular to the anterior border of masseter, especially on the surface of the zygomatic process. The important reason is that: the structure of the zygomatic process is complex; SMAS becomes thinner here and crowding together with bundles of zygomatic ligaments to form a patch. While the zygomatic branch of facial nerve, and the parotid duct runs thin and superficial without the protection of accessory parotid gland. Continue to dissect forward, and it is important to make the separation layer exactly: the orbicularis muscle is separated under its deep surface, and the zygomatic major is the separation at its superficial surface. At this point, finger technique is usually performed until dissecting into the premasseter space [5], after which a slight separation at the surface of the zygomaticus major will signified the high-SMAS flap is separated successfully .

\section{Results}

In all the 18 cases followed up, most (11/18) obtained a clear mandibular margin after operation and scored full mark; perfect nasolabial fold improvement was achieved in few (7/18). In terms of "ogee curve" evaluation, most (15/18) made it to the level of "acceptable", which was shared by the evaluation of lower eyelid shortening effects (13/18). Detailed surgical outcome evaluation was presented in Table 2. Of all the six evaluated items in the 18 patients, mandibular margin (A) scored highest, 
Table 2. Surgical outcome evaluation of 18 follow-up cases

\begin{tabular}{lllllc}
\hline \multicolumn{1}{c}{ Evaluated items } & \multicolumn{1}{c}{ Perfect } & \multicolumn{1}{c}{ Good } & Acceptable & Unimproved & Average \\
\hline Jowl line (A) & 11 cases A1 $=33$ & 5 cases A2 $=10$ & 2 cases A3 $=2$ & 0 case & $2.5 / 3$ \\
Ogee curve (B) & 0 case & 5 cases B2 $=7.5$ & 13 cases B3 $=13$ & 0 case & $1.1 / 2$ \\
Nasolabial fold (C) & 3 cases $\mathrm{C} 1=6$ & 7 cases C2 $=10.5$ & 6 cases C3 $=6$ & 0 case & $1.3 / 2$ \\
Jowl (sagging of jowl) (D) & 8 cases D1=8 & 5 cases D2 $=4$ & 3 cases D3 $=1.5$ & 2 cases D4=0 & $0.8 / 1$ \\
Submental fullness (E) & 10 cases E1 $=10$ & 4 cases E2 $=3.2$ & 4 cases E3 $=2.0$ & 0 case & $0.8 / 1$ \\
Lower eyelid shortening (F) & 0 case & 1 case F2 $=0.8$ & 13 cases F3=6.5 & 4 cases F4=0 & $0.5 / 1$ \\
\hline
\end{tabular}
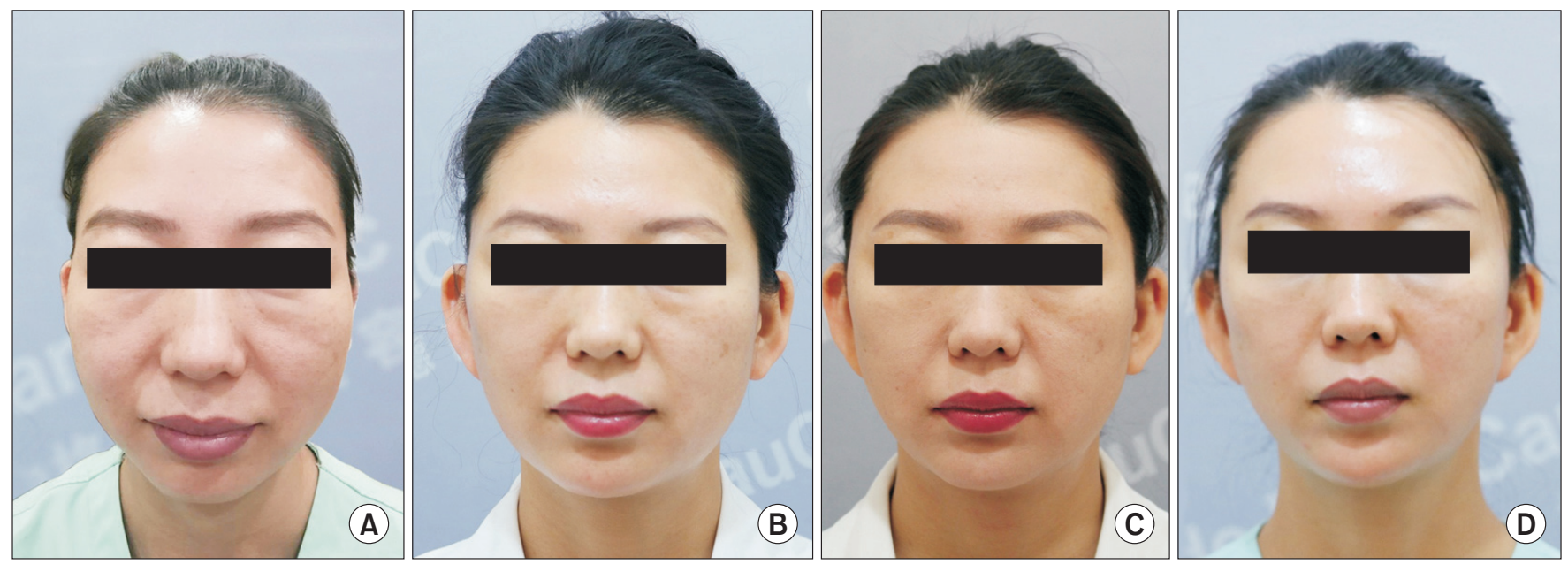

Fig. 8. Preoperative and postoperative photographs of a volunteer. (A) Preoperative, (B) 3 months after hemifacial facelift, the right side is the surgical side, the left side is not operated. (C) 6 months after hemifacial facelift, the right side is surgical, the left side is not. (D) The right side is 12 months after facelift, the left side is 5 months after surgery.

with an average (2.5) between A1 ("perfect") and A2 ("good"). "Ogee curve" (B) and lower eyelid shortening (F) scored lowest, averaging 1.1 and 0.5 , respectively, signifying only "acceptable" effects $(B 3=1, F 3=0.5)$. The other three items achieved either "perfect" (D and E) or "good" (C) effects.

\section{Discussion}

\section{Why can high SMAS flap achieve desirable tightening effects?}

The vertical lift of high SMAS flap can rotationally raise midface soft tissues, mainly zygomatic fat pad, and is therefore effective in uplifting lateral soft tissues in midface [6,7] (Fig. 8). The lifting effect depends on how well zygomatic ligaments are dissected and cut which is the trickiest and most important part in SMAS plasty. It usually relies on experience and feeling, like its other counterparts, because zygomatic ligaments share the same color with neighboring tissues [2] and cannot be distinguished only with visual observation. The dissection and cutting off these tissues will have to rely on our experience and feeling, because they have difference in texture but similarity in color. Zygomatic ligaments are accompanied by zygomatic branch of facial nerve and transverse facial artery, hence both extreme caution and proficient anatomical knowledge are essential.

The vertical uplift of big and high SMAS-platysma flap, and this force is fully conveyed to the mandibular margin and neck, which is a direct force to lift the flap. That is why the rejuvenation of lower face and mandibular region is certainly desirable. A clear mandibular margin is the most noteworthy result of this surgery. In addition to the high SMAS-platysma flap directly, the platysma plasty is also indispensable. Platysma plasty contributes $1 / 3$ to the improvement of mandibular margin and determines whether submental fullness can be effectively resolved (Fig. 8). In other words, without it, postoperative improvement of mandibular margin and submental fullness will be far discounted.

In fact, a clear and smooth mandibular curve is the most significant indicator of cervical rejuvenation. Based on longtime observation and research, the authors designated 3 points 
to "perfect" mandibular improvement which is $30 \%$ of the full mark (3/10) for this facial rejuvenation evaluation standard. However, it is worth noting that previous research on this topic either neglected or underestimated the difficulty and necessity of mandibular rejuvenation.

To obtain a clear mandibular margin means that: 1 . Soft tissues on the surface of the mandible, which belongs to the lower face, should be tightened, and drooping mouth corners that are the main indicator of aging need to be resolved. Both require the dissection and tightening of platysma and BFP in the premasseter space. 2. Heavily drooping submandibular platysma and skin should be tightened effectively, which calls for two necessary procedures. The first procedure is the skin needs to be dissected in a large scope to enable an effective and sufficient uplifting. Therefore, mandibular ligaments [2] will have to be dissected and cut. The other procedure was the platysma had to be sutured in two directions to sharpen the obtuse cervico-mandibular angle. One direction is achieved by the locking suture of the anterior edges of platysmas in the median line [3] while the other direction is guaranteed by the lateral tightening of platysma flap below the mandibular angle (Fig. 9). By now it is clear that to score 3 points (the full mark for this item) in the rejuvenation of the mandibular margin is challenging and requires a number of techniques.

\section{Is there anything high SMAS face lift fails to achieve?}

The answer is unfortunately yes. Desirable as this high SMAS technique is, but it is not perfect. As shown in Table 2, "ogee curve" (B) and lower eyelid shortening (F), whose improvement is correlated, failed to score a single case of "perfect". Both of the improvements only make it to "acceptable" in majority, a passable effect that comes from lipofilling during the surgery (including nasolabial fold filling). In midface, which is lateral to the nose, this high SMAS technique failed to achieve "perfect" or "good" rejuvenation, contrary to the case of lateral midface and the region across the mandible. This was due to the differences of our high SMAS face lift from that of Barton [8]: 1. Suspension of midface and orbicularis oculi muscle through incising inferior palpebral margin [9] was not performed in our study. 2. Unlike Barton's European and American patients who are usually slim, Chinese patients are troubled with fattening in an aging face which limits the mobility of soft tissues and results in poor tightening effects. 3. Comparing with Caucasian people, the Chinese have stronger facial ligaments that leads to better retaining effects. However, these arguments are faulted in that they are the authors' personal observation after performing 8 cases of face lift for Caucasian people instead of the results of comparative studies. But there is no study results on design to do scientific comparison. This is what that is lacking in this article.

Although the acceptable "ogee curve" in midface is not achieved by this high SMAS face lift, the authors still believe that the midface rejuvenation of "ogee curve" is one of the most important objective indicators. That is also why a 2-point full mark is designated to this item. "Ogee curve" refers to a threedimensional curved surface with both vertical and horizontal arches. Plastic surgeons in China sometimes call it the "apple muscle". Although it looks like apple, "ogee curve" mainly consists of fat tissues and involves few muscles [7]. It is formed of a number of fat structures surrounding the prezygomatic space,
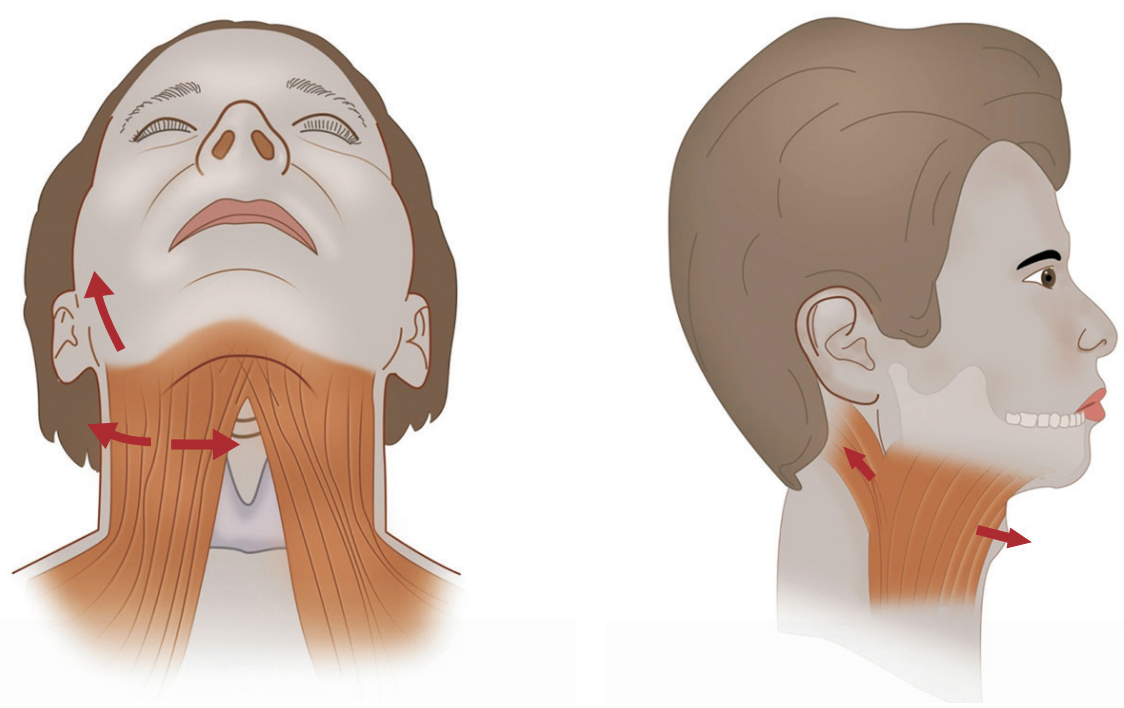

Fig. 9. The platysma flap is tightened in 3 directions. 
preseptal space, maxillary space, and buccal space [5]. Therefore, in addition to tightening, volumetric treatment should also be deployed in the rejuvenation of "ogee curve".

\section{Conflicts of interest}

The authors have nothing to disclose.

\section{References}

1. Furnas DW. The retaining ligaments of the cheek. Plast Reconstr Surg 1989;83:11-6.

2. 王志军, 高景恒, 李吉. 面部韧带的解剖学研究 [J]. 实用整形美容外 科杂志 1992;3:127-30.

3. Feldman JJ. Neck lift. St Louis, MO: Quality Medical Publishing; 2006.
4. 王志军, 王毅彪, 夏成俊, 李衍江, 高景恒, 李吉. 题区筋膜结构分析 [J]. 实用美容整形外科杂志 1992;3:205-7.

5. Mendelson BC, Jacobson SR. Surgical anatomy of the midcheek: facial layers, spaces, and the midcheek segments. Clin Plast Surg 2008;35:395-404.

6. Barton FE Jr. Rhytidectomy and the nasolabial fold. Plast Reconstr Surg 1992;90:601-7.

7. 王志军，高景恒，李吉. 面部表浅肌肉键膜系统的解剖学研究 [J]. 实 用整形美容外科杂志 1992;3:115-8.

8. Barton FE Jr. The "high SMAS" face lift technique. Aesthet Surg J 2002;22:481-6.

9. Kang KJ, Yang HH, Chai CY. Assessment of rejuvenation by change of lid-cheek junction after transconjunctival and traditional subciliary incision blepharoplasty. J Cosmet Med 2017;1:30-8. 